\title{
A Call for Holistic Soil Ecology
}

\author{
Barbara J Dilly* \\ Professor Emerita, Department of Cultural and Social Studies, Creighton University, Omaha, Nebraska, USA
}

*Corresponding author: Barbara J Dilly, Professor Emerita, Department of Cultural and Social Studies, Creighton University, Omaha, NE 68178, Nebraska, USA
Received Date: August 17, 2020

Published Date: September 03, 2020

\section{Editorial}

The connections between agriculture, soil science, and human health have been well understood for centuries, but the development of state societies and market economies gradually segmented and subverted that knowledge into narrow specializations. Agriculture came under management of nation builders seeking to broaden productive capacities to further influence and power. Soil science was relegated to the laboratories and test plots of biology and chemistry in the adoption of hybrids and chemical fertilizers. Human health sciences compiled volumes of research on disease, which generated still more laboratory research on isolated cures through chemical intrusion.

Despite of all this knowledge segregation, alternative agriculture and alternative health practitioners kept a holistic focus. But they were not the ones who set policy. In fact, they were labeled as subversives to civilization and its progress. Then add in the environmentalists who also got it, and you have a bunch of radicals. Or so some people thought. These radicals didn't seem to understand the primacy of the profit motive. Nor did they pay homage to the hegemony of political regimes and industrial complexes. Their knowledge was repressed even by universities, who by relegating relevant questions in our society to narrow disciplines and marginalizing interdisciplinary scholars, kept the big picture of the future of our planet out of view. Back to the microscope!

But a lot is changing. Now, in the 21st century, the ancients, the anarchists, and the activists all over the world are combining forces to mobilize massive and highly relevant grass roots movements of sustainable agriculture with the ambitious but essential purpose of healing the soil, the environment, and human health all at the same time. It is because it is all sick, in critical condition, and could die. These outsiders to "systems" are making a difference, because the knowledge on all these topics converges. As a cultural anthropologist who has spent my entire career understanding agricultural systems, human health, and environmental health, I have studied their problems and responses all over the world. Everywhere it is obvious that you can't effectively work on any one of these problems without working on all of them. And the starting point is always the same. Soil health.

My challenge to your journal is to seek more holistic articles that evaluate the relationships between agriculture, soil science, the environment, and human health and how they work in practical contexts. Publish articles that evaluate what works and what doesn't work in the big picture. In every instance, poor soil health threatens agricultural systems, local ecologies and human health. A more holistic, and aggressive approach to the study of agriculture soil science should yield better policy that focuses on not just greater commodity production but also resource sustainability as well as human health. Our very lives and the life of the planet depends on a holistic approach.

\section{Acknowledgement}

None.

\section{Conflict of Interest}

No conflict of interest. 